\title{
Preface
}

\section{Ventricular Tachycardia in Structural Heart Disease}

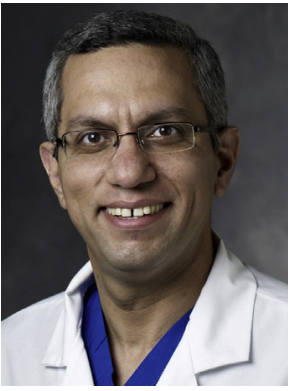

Amin Al-Ahmad, MD

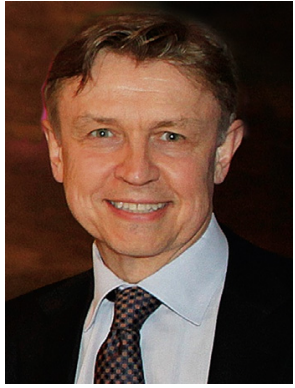

Francis E. Marchlinski, MD
Editors

This issue of Cardiac Electrophysiology Clinics is focused on ventricular tachycardia in patients with structural heart disease. We are fortunate to have a group of experts and leaders in the field contribute the latest knowledge in this area. The issue begins with an article on electrocardiogram localization as well as an article on anatomic considerations, important when contemplating an ablative strategy for management of ventricular tachycardia patients.

Next, considerations specific to ablation in patients with ischemic heart disease as well as those with nonischemic heart disease are discussed. Techniques such as entrainment mapping, pace mapping, and substrate ablation are also covered in subsequent articles. In addition, an article is dedicated to techniques that may be useful when standard ablation is unsuccessful, such as surgical ablation and alcohol ablation.

Specific disease states that may have unique challenges are also discussed in an article on arrhythmogenic right ventricular dysplasia as well as an article on ablation of ventricular tachycardia in patients with congenital and infiltrative heart disease.

An article on the important aspects of epicardial ablation is also covered, as is premature ventricular contaction ablation in patients with structural heart disease, and the use of hemodynamic support during ablation procedures.

This issue is complete with an article detailing clinical trials in ventricular tachycardia ablation.

We are confident that this issue will be relevant to cardiac electrophysiologists and cardiac electrophysiology trainees as well as all clinicians interested in the management of ventricular tachycardia.

Amin Al-Ahmad, MD Texas Cardiac Arrhythmia Institute 3000 North IH35, Suite 700

Austin, TX 78705, USA

Francis E. Marchlinski, MD Hospital of the University of Pennsylvania University of Pennsylvania Health System University of Pennsylvania

3400 Spruce Street

9 Founders Pavilion

Philadelphia, PA 19104-4283, USA

E-mail addresses: aalahmadmd@gmail.com (A. Al-Ahmad) Francis.Marchlinski@uphs.upenn.edu

(F.E. Marchlinski) 